\title{
El trabajo directivo en educación primaria: liderazgo, procesos participativos y democracia escolar
}

\author{
David Manuel Arzola Franco \\ Centro de Investigación y Docencia \\ Carmen Griselda Loya Ortega \\ Centro Chihuahuense de Estudios de Posgrado \\ Ana María González Ortiz \\ Centro de Investigación y Docencia
}

\section{Resumen}

I presente trabajo contiene los $\checkmark$ resultados de un estudio etnográfico, desarrollado a partir de un convenio de colaboración interinstitucional entre los Cuerpos Académicos de "Política y Gestión en Educación" del Centro de Investigación y Docencia y "Cambio Educativo" del Centro Chihuahuense de Estudios de Posgrado.

El estudio tiene el propósito de recuperar las concepciones que los actores educativos, que laboran en escuelas primarias de tres municipios del estado de Chihuahua, han construido con respecto a la dirección escolar, el liderazgo, el manejo de conflictos, el diálogo y la participación democrática.

Los datos recabados indican que el discurso de la participación democrática se ha instalado en los colectivos escolares, valoran a los directivos que abren las oportuni- dades de colaboración, que crean ambientes de confianza, cultivan la solidaridad y el desarrollo profesional del profesorado. Al mismo tiempo, critican y denuncian las prácticas autoritarias, la unidireccionalidad en la toma de decisiones y la escasa resonancia que puede tener la acumulación de títulos y certificados en el mejoramiento del trabajo directivo.

Paradójicamente, en la mayoría de los discursos recabados, hay una concepción jerárquica y normativa sobre la dirección escolar, aunque elogian la apertura y el diálogo, reclaman un liderazgo fuerte que ponga orden. La emergencia de liderazgos paralelos se asocia con el conflicto y las tensiones políticas al interior de las escuelas, puesto que retan a la autoridad formalmente establecida.

Palabras clave: Directores, participación del profesor, democracia, autoritarismo, liderazgo. 
REVISTA DE INVESTIGACIÓN EDUCATIVA DE LA REDIECH N. 12 ISSN: 2007-4336

\section{Introducción}

Históricamente, las concepciones sobre la naturaleza de la tarea directiva han evolucionado de la imagen del director como un administrador, con una función esencialmente burocrática (Pozner, 2005), pasando por las nociones de dirección eficaz, hasta la visión compleja de una dirección para el cambio (Murillo, 2006), o bien como señala Álvarez (2003) se ha transitado "desde un estilo autocrático a un estilo participativo" (p. 5). En este proceso las teorías del liderazgo han sido particularmente influyentes (Maureira, 2006) y han contribuido en la configuración de los perfiles directivos o de los modelos de dirección escolar.

Como respuesta a las posturas estáticas que privilegian la definición de funciones, el marco normativo y la identificación de las características individuales del líder, los enfoques teóricos contemporáneos, como el del liderazgo transformacional (Bass, 1988), el enfoque micropolítico (Ball, 1994) o el liderazgo distribuido (Spillane, 2006), señalan que la tarea de un directivo está indisolublemente unida a los ámbitos cultural, político, ideológico y organizativo de los centros escolares. Es decir, no se trata de un ente aislado, es el contexto escolar, con sus valores, idiosincrasia, creencias y prácticas, las relaciones de poder, su estructura y formas de operar, las que dan sentido a la labor cotidiana de los directores.

Por otra parte, el trabajo directivo ha sido consignado por la literatura especializada como un elemento central en la configuración de las dinámicas de los esta- blecimientos escolares (Álvarez, 2003; Del Arco, 2007; Fernández, 2007), los directores "son pieza clave para planear, coordinar y sostener, junto con el colectivo docente, la autonomía de gestión de la escuela y la mejora de los procesos de enseñanza" (SEP, 2015:13). Las investigaciones sobre eficacia escolar, por ejemplo, señalan al director como un componente fundamental en la consecución de los objetivos y metas educativas (Maureira, 2006; Murillo Torrecilla, 2006).

Esta condición de "pieza clave" coloca a estos sujetos en medio de la avalancha de demandas dirigidas a la escuela, que se vinculan con la perenne crisis que viven las sociedades contemporáneas, caracterizadas por el acelerado desarrollo tecnológico, la recurrencia de los problemas económicos, el deterioro ambiental, el descrédito de la política gubernamental, la pobreza extrema, la violencia exacerbada; la manera tan vertiginosa en que los cambios se suceden y la incertidumbre que ello acarrea.

Ante este mundo cambiante e incierto, la educación es señalada como una de las vías indispensables para atender el estado de emergencia. Consecuentemente, el trabajo directivo se expande, se diversifica y se torna cada vez más complejo y azaroso. Pozner (2005) recoge algunos aportes relacionados con la multiplicidad de tareas que competen a un director: orientador, promotor de valores, enlace, gestor, planificador, negociador, formador, administrador. Para Fernández (2007:30) la dirección para el cambio "precisa romper modelos jerárquicos todavía vigentes, promover el desarrollo del conocimiento y el cambio en 
las organizaciones educativas, corresponsabilizar al personal, impulsar la innovación y profesionalizar la acción de gestión del centro a través de sistemas planificados y documentados".

Para dar otra vuelta de tuerca, en el caso de México, al entrar en vigor la Ley General del Servicio Profesional Docente, la permanencia en la función está condicionada a un proceso de evaluaciones periódicas, basadas en los "perfiles, parámetros e indicadores" (DOF, 2013) que definen las características que el Estado determina para el ejercicio de esta responsabilidad:

...los directivos deben contar con conocimientos sólidos sobre el contenido de los planes y programas de estudio, los procesos de aprendizaje de los alumnos, las prácticas de enseñanza, la autonomía de gestión escolar, el desarrollo profesional, los principios legales y filosóficos que sustentan el servicio público educativo, la atención a la diversidad sociocultural y lingüística de los alumnos, así como la relación entre la escuela y la comunidad (SEP, 2015:13).

A pesar de la manera tan prolija con que se describen estas funciones, es obvio que entre el deber ser y las acciones concretas existen zonas opacas o veladas que requieren visibilizarse para comprender la práctica de estos agentes educativos. La presente investigación tiene el propósito de brindar un acercamiento a la visión que los propios sujetos relacionados con la tarea educativa -docentes, supervisores escolares, Asesores Técnico Pedagógicos (ATP) y los propios subdirectores y directores-, han construido en torno al quehacer directivo, a partir de un estudio realizado en el nivel de educa- ción primaria de tres municipios: Juárez, Ahumada y Chihuahua capital.

\section{Consideraciones metodológicas}

Los resultados de esta investigación, se derivan de un proyecto realizado de manera conjunta por un grupo de académicos del Centro de Investigación y Docencia y del Centro Chihuahuense de Estudios de Posgrado, en el que participaron diez investigadores y tres grupos de estudiantes de los posgrados que ofertan ambas instituciones.

En el plano metodológico, se propuso abordar el estudio desde una perspectiva etnográfica, para lo cual se trabajó con los registros producto de seis meses de observación diaria en 21 escuelas primarias. A ello se suma el análisis de 82 entrevistas individuales no estructuradas en las que participaron 61 docentes, ocho directores, cinco supervisores y tres jefes de sector, así como cinco ATP.

La metodología empleada permitió documentar diversas dinámicas presentes en las escuelas primarias, además de recuperar las impresiones de los agentes antes mencionados con relación al papel de los directivos, de tal forma que se generó "un proceso reflexivo que operó en todas las etapas del desarrollo de la investigación" (Hammersley y Atkinson, 1994:42) mismo que posibilitó el análisis interpretativo que se incluye en la presente ponencia.

\section{Análisis y discusión de resultados}

El director de una escuela requiere cierta sutileza, tacto y olfato para enfrentar los problemas que se presentan de manera co- 
tidiana; varios de los testimonios de profesores señalan que en un director es indispensable el mando o autoridad, es decir se requiere dirección, alguien que fije rumbo:

...normalmente se concibe al líder de una escuela como una autoridad fuerte, pero creo que un buen líder es el que sabe manejar una buena organización, toma decisiones justas y propone el trabajo en equipo, establece buenas relaciones y es proactivo. He tenido la oportunidad de trabajar con dos directivos escolares y hasta ahorita he tenido buenas experiencias, me pongo en su lugar al encontrar un equilibrio entre ser una figura de autoridad y llevar una buena organización escolar (Profesor; 69:4; 125:127).

La diplomacia es una de las herramientas básicas para el liderazgo directivo. Aunque se requiere del respeto que impone una autoridad fuerte, este debe complementarse con el manejo inteligente de las relaciones con el colectivo escolar:

...yo pienso que aquíla relación laboral y con padres de familia y alumnos es buena, no puedo decir excelente, pero puedo decir que es muy buena y yo lo relaciono directamente con el liderazgo de la directora... ella tiene un liderazgo excelente... los conflictos, aunque aparezcan, se resuelven a tiempo y en forma (Profesor, 35:4, $72: 72)$.

La demanda por una figura de autoridad en el director es recurrente en los testimonios recabados, un director fuerte, que confía en su liderazgo, transmite esa seguridad al personal, genera sinergias y ayuda a precisar los objetivos y metas con mayor claridad; fijar el rumbo se configura entonces como la piedra angular de la tarea directiva, no en vano rumbo, orientación y dirección son sinónimos.

Aunque resulta siempre complejo, la búsqueda del equilibrio y el diálogo son dos elementos importantes que se destacan en los testimonios recabados, ello implica relaciones horizontales y la construcción de una cultura participativa en la que la crítica constructiva juega un papel fundamental: “...yo siempre he visto que hay democracia, que la toma de decisiones se da en un marco abierto para todos, no es, no es autoritaria" (Profesor, 35:7, 82:82).

Hay un énfasis especial en el diálogo constructivo, como mecanismo que abre oportunidades para la formación y el desarrollo profesional de los docentes dentro de las instituciones, se aprovecha la experiencia y conocimiento del colectivo escolar. Un director que está seguro de su autoridad, que no teme mostrar su ignorancia respecto a determinados temas, aprovecha el impulso creador de su personal y potencia las oportunidades para la mejora, lo anterior implica delegar tareas y compartir las responsabilidades:

Creo que necesitamos nosotros fortalecer ese liderazgo, no tenemos nosotros la capacidad de delegar responsabilidad en otros compañeros, a veces es que ya se vienen arrastrando cosas que no nos permiten... el delegar responsabilidad en alguien, porque finalmente el directivo tiene temor porque él es responsable de lo que suceda en la escuela (Supervisora; $15: 7 ; 56: 56)$.

Se destaca que el liderazgo y la colaboración son ingredientes sustanciales para el buen funcionamiento institucional; la confianza completa el triángulo que refuerza el 
pacto social de las instituciones escolares. $\mathrm{Al}$ respecto, se encuentran evidencias del papel destacado que juega la parte afectiva, las relaciones personales y el respeto mutuo en el desarrollo académico de las escuelas:

... hay mucha confianza... la directora es una compañera que acaba de subir a directora apenas bueno ya tiene dos años, mucha gente creyó que a lo mejor por la amistad iba a haber esa actitud como de que hago como que trabajo y fíjate que no. Bueno al menos la actitud de la mayoría cuando hablamos entre nosotros decimos te sientes más presionada por el hecho de que como fue tu compañera tu amiga, no quieres que quede mal existe ese compromiso entonces (Profesor, 28:12, 86:86).

La confianza tiene su origen en los lazos afectivos construidos en la convivencia diaria, en el caso descrito, la directora no es una extraña en la escuela, los docentes conocen su trayectoria, han creado vínculos y compromisos previos. Sin embargo, cuando se trata de un director externo, la construcción de la confianza es una parte fundamental de su tarea, el documento que lo acredita como director no lo hace el líder del establecimiento, es el personal de la escuela el que lo legitima y le da su confianza:

...pues caray, pues está difícil... porque el liderazgo se gana, el liderazgo se... no se impone, se gana así que, pues no es posible manejarlo así, yo considero más bien que el liderazgo lo tiene el director y él nos guía (Profesora; 66:16; 122:123).

Que la legitimidad la dé el colectivo, implica que el liderazgo está siempre a prueba, los directivos, al menos los que aspiran a un ejercicio democrático de su función, deben demostrar cotidianamente su capacidad para fijar el rumbo institucional:

...yo procuro llegar a negociaciones... procuro que los acuerdos se cumplan, que estén bien los niños, porque por ellos estamos ahí, por ellos tomamos esta carrera, por ellos nos están pagando, por ellos tenemos o estamos donde estamos, y ya de ahí surge lo demás (Director; 122:12; 164:165).

Los participantes destacan la conformación de una comunidad solidaria como medio para construir un ambiente de trabajo con el que los colectivos escolares se sienten identificados; pero el trabajo directivo no es solo una cuestión de buena voluntad, la confianza, el respeto, la autoridad, se construyen a partir del trabajo, de lo contrario se cae en un ambiente de relajamiento, de ausencia de dirección: "haga de cuenta como si no existiera, él nunca sabe nada, no hace nada, no conoce nada... es una vergüenza que teniendo ya su clave de subdirector no pueda realizar su trabajo"(Profesora, 66:10;102:103).

Los elementos entrópicos son una sombra que amenaza de manera permanente la organización escolar, la confrontación y la discordia entre los integrantes de un colectivo son evidencias de la naturaleza política que atraviesa las relaciones en una comunidad educativa. De ahí la necesidad expresa de tener un directivo que dé cauce a las inquietudes y tensiones, que disponga de los medios para propiciar el diálogo, los acuerdos y consensos, de lo contrario se corre el riesgo de llevar al extremo el ejercicio de la autoridad, es decir, convertirse en una figura autoritaria. 
La vida participativa implica un reto mayor para los colectivos escolares, puesto que cambia la distribución del poder, desplazando la idea de la autoridad unipersonal por un modelo distribuido y de corresponsabilidad. Pero estas propuestas al implantarse en ambientes que tradicionalmente han sido gobernados de manera autoritaria, son visualizadas como potencialmente peligrosas para la autoridad formal. Al abrir los espacios para la participación se abre también la puerta a liderazgos paralelos, y con ello la oportunidad de construir ambientes cooperativos, pero también climas de tensión y enfrentamiento. Esto habla de los límites de las propuestas participativas implantadas en un clima autoritario o con una democracia incipiente:

...el directivo... no sabía cómo guiar, entonces yo propongo pararme y decirles a los maestros... darles motivación a los maestros... y se acerca el directivo a mí y me dice: “¡No, quite eso!" ...entonces le digo "sí profe, sí es resultado debido a que sí hay cosas buenas o cosas malas, es un resultado, por lo tanto, hay una necesidad que se tiene que adecuar". Y él me decía: “¡No, no, bórrela no es un resultado!", entonces a mí me pareció incorrecto... que le dijera a la secretaria que tenía que escribir ciertas cosas como él pensaba (Profesor, 13:7, 30:30).

El testimonio anterior hace patente la tensión entre la autoridad deóntica y la autoridad epistémica, es decir la autoridad impuesta normativamente, la autoridad del que manda, contra la autoridad que da el saber. El conocimiento suele ser también un recurso para consolidar el liderazgo directivo o, por el contrario, cuestionarlo: ...también ha habido cursos en los que mandan al director a que medio se prepare y luego nos da el curso a nosotros. Y ahí se me afigura (sic) que el director en una semana no se alcanza a preparar totalmente como para presentar el curso a sus maestros, y hay veces que nomás van los maestros a platicar (Profesor, 123:1, 86:86).

La autoridad epistémica como elemento legitimador de los liderazgos, pone de manifiesto la necesidad de una formación sólida en los cuerpos directivos, enfocada en la consolidación de comunidades académicas con un alto sentido autocrítico, que potencien la capacitad creadora, innovadora o transformadora que emerge de colectivos plurales y democráticos. El problema radica en la tendencia credencialista, el saber aparente que da la acumulación de los títulos, diplomas y grados, que suele redituar en términos de escalafón, posiciones de autoridad y retribución económica, pero que tienen escasa resonancia en el mejoramiento de las prácticas. Los docentes enfatizan que la acreditación no es una garantía del saber:

...aquí en primaria hay maestros que tienen muchos títulos, muchos directores que no deberían estar como directores aquí en la zona, muy preparados, según ellos, pero pues su práctica no funciona, no sirve porque no son capaces de darse cuenta de los problemas que hay en la escuela (Profesora, 66:1, 77:77).

\section{Reflexiones finales}

El material empírico da cuenta de la tensión política siempre presente, el conflicto de manera manifiesta o soterrada 
es un ingrediente esencial en la dinámica de los establecimientos educativos. En el caso concreto que nos ocupa el problema ha sido abordado exclusivamente desde el punto de vista de los directivos frente al colectivo, pero este último suele desdoblarse también en grupos y subgrupos con intereses y posiciones divergentes y hasta antagónicas, que de no ser abordadas de manera adecuada pueden desencadenar efectos no deseados para la vida institucional y, por ende, dificultades en el logro de los propósitos educativos.

En la información recabada se destaca el valor que los colectivos escolares dan a los espacios de participación democrática y los ambientes colaborativos. Realzan las cualidades de aquellos directivos que tienen la capacidad de construir ambientes dialógicos y equilibrados, donde la confianza, el compromiso y la solidaridad se construyen a través de vías diplomáticas con fuerte énfasis en los elementos afectivos.

Pero, implícitamente, en la mayoría de los discursos recabados, hay una concepción jerárquica sobre la dirección escolar. Aunque reconocen el valor de la participación, paradójicamente aceptan de manera tácita la condición de subordinación y la necesidad de un liderazgo fuerte que imponga respeto, guíe y, en última instancia, decida por los demás. La idea de un liderazgo múltiple, distribuido, resulta en algunos casos amenazante y conflictiva. Quizá la raíz de esta contradicción pueda rastrearse en la rigidez de los elementos estructurales del sistema educativo mexicano, caracterizado por la verticalidad y el centralismo, y en la cultura antidemocrática que tradicionalmente se ha cultivado y permea todavía en los centros educativos.

\section{Referencias}

Álvarez, M. (2003). La dirección escolar en el contexto europeo. Revista Organización y Gestón Educativa, 11(2), 1-5.

Ball, S. (1994). La micropolítica de la escuela. Hacia un teoría de la organización escolar. Barcelona: Paidós.

Bass, M. (1988). El impacto de los directores transformacionales en la vida escolar. En R. Pascual Pacheco, La gesitión escolar ante la innovación y el cambio (pp. 26-36). Madrid: Narcea.

Del Arco, M. (2007). Los directores de los centros escolares en el sistema educativo. Revista cuatrimestral del Consejo Escolar del Estado(5), 18-22.

DOF. (11 de 09 de 2013). Ley General del Servicio Profesional Docente. Diario Oficial de la Federación, Art. 52, parr. 3.

Fernández Díaz, M. (2007). La dirección escolar ante los retos del siglo XXI. Revista cuatrimestral del Consejo Escolar del Estado(5), 23-38.

Hammersley, M. y Atkinson, P. (1994). Etnografía, métodos de investigación. Barcelona: Paidós.

Maureira, O. (2006). Dirección y eficacia escolar, una relación fundamental. Revista electrónica iberoamericana, sobre calidad, eficacia y cambio en educación, 4(4), 1-10.

Murillo Torrecilla, J. (2006). Una dirección para el cambio: del liderazgo transformacional al liderazgo distribuido. Revista electrónica iberoamericana sobre calidad, eficacia y cambio en educación, 4(4), 11-24.

Pozner de Weinberg, P. (2005). El directivo como gestor de aprendizajes escolares. Buenos Aires: Aique.

SEP. (2015). Pefril, parámetros e indicadores para pesonal con funciones de dirección y de supervisión. México: Secretaría de Educación Pública.

Spillane, J. (2006). Distributed Leaderchip. London: Jossey-Bass. 